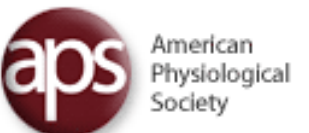

\title{
Cytokine-induced F-actin reorganization in endothelial cells involves RhoA activation
}

\author{
$\underline{\text { Silvia B. Campos }},{ }^{1,{ }^{*}}$ Sharon L. Ashworth,,${ }^{1,3,{ }^{*}}$ Sarah Wean, ${ }^{1}$ Melanie Hosford, ${ }^{1, \dagger}$ Ruben M. Sandoval, ${ }^{1}$ Mark A. Hallett, ${ }^{1}$ \\ Simon J. Atkinson, ${ }^{1}$ and Bruce A. Molitoris ${ }^{1,2}$ \\ ${ }^{1}$ Department of Medicine, Division of Nephrology, Indiana University School of Medicine and the ${ }^{2}$ Roudebush Veterans Affairs Medical Center, \\ Indianapolis, Indiana, ${ }^{3}$ Department of Biochemistry, Microbiology, and Molecular Biology and School of Biology and Ecology, University of Maine, \\ Orono, Maine \\ * S. B. Campos and S. L. Ashw orh contributed equally to this work. \\ †Deceased. \\ Address for reprint requests and other correspondence: S. J. Atkinson, Div. of Nephrology, Dept. of Medicine, Indiana Univ. School of \\ Medicine, 950 West Walnut St., R2-202, Indianapolis, IN 46202 (e-mail: satkinso@iupui.edu)
}

Received March 4, 2008; Accepted January 9, 2009.

Copyright $@ 2009$, American Physiological Society

\section{Abstract}

Acute ischemic kidney injury results in marked increases in local and systemic cytokine levels. IL-1a, IL-6, and TNF- $\alpha$ orchestrate various inflammatory reactions influencing endothelial permeability by altering cell-to-cell and cell-to-extracellular matrix attachments. To explore the role of actin and the regulatory proteins RhoA and cofilin in this process, microvascular endothelial cells (MS1) were exposed to individual cytokines or a cytokine cocktail. Within minutes, a marked, time-dependent redistribution of the actin cytoskeleton occurred with the formation of long, dense F-actin basal stress fibers. The concentration of F-actin, normalized to nuclear staining, significantly increased compared with untreated cells (up 20\%, $P \leq 0.05$ ). Western blot analysis of MS1 lysates incubated with the cytokine cocktail for $4 \mathrm{~h}$ showed an increase in phosphorylated/inactive cofilin (up $25 \pm 15 \%, P \leq 0.05$ ) and RhoA activation (up to $227 \pm 26 \%$ increase, $P \leq 0.05$ ) compared with untreated cells. Decreasing RhoA levels using small interfering RNA blocked the effect of cytokines on stress fiber organization. Treatment with Y-27632, an inhibitor of the RhoA effector p160-ROCK, decreased levels of phosphorylated cofilin and reduced stress fiber fluorescence by $22 \%$. In cells treated with Y-27632 followed by treatment with the cytokine cocktail, stress fiber levels were similar to control cells and cofilin phosphorylation was $55 \%$ of control levels. Taken together, these studies demonstrate cytokine stimulation of RhoA, which in turn leads to cofilin phosphorylation and formation of numerous basal actin stress fibers. These results suggest cytokines signal through the Rho-ROCK pathway, but also through another pathway to affect actin dynamics.

Keywords: ADF/cofilin, acute kidney injury, ischemia, p160-ROCK, inflammation

THE INTRICATE ARCHITECTURE of the actin cytoskeleton responds to normal and pathological extracellular stimuli through signaling cascades. In response to these stimuli, the activity of regulatory proteins that regulate polymerization and depolymerization of actin filaments that link the filaments to form bundles and gels and link actin filaments to the plasma membrane is altered (22). The RhoA signaling cascade plays an important role in regulating actin cytoskeletal organization and dynamics, inducing actin stress fiber and focal adhesion formation (11). The Rho family of GTPases is a member of the RAS gene 
superfamily of p21 GTPases. These proteins act as molecular switches, cycling between their GTP- and GDP-bound states (active and inactive, respectively). In the active state, RhoA stimulates effectors, including the serine-threonine kinase p160-ROCK, which phosphorylates and activates downstream targets including LIMK1 $(9, \underline{15}, \underline{19})$. LIMK1 in turn phosphorylates and inactivates the actindynamizing proteins, actin-depolymerizing factor (ADF) and cofilin $(\underline{1}, 32)$. Phosphorylated ADF/cofilin proteins cannot depolymerize or sever actin filaments, resulting in a decreased turnover in actin filaments (4). However, in disease states such as renal ischemia this finely regulated signaling cascade is disrupted, resulting in abnormally high levels of unphosphorylated ADF/cofilin proteins, mediating actin cytoskeleton breakdown and disorganization $(\underline{2}, \underline{24})$.

Renal ischemic injury, a condition characterized by compromised blood flow to the kidney, results in tissue anoxia, reduced intracellular ATP levels, and the production of cytokines (25). With ischemic injury, the normal architecture of the actin cytoskeleton is markedly changed along with endothelial cell swelling, impaired cell-cell and cell-substrate adhesion, and loss of tight junction barrier function ( $\underline{6}$, 28). Filamentous actin is lost from the cortical actin network, junctional complexes, and stress fibers, accompanied by marked increases in F-actin aggregates in the basal and basolateral regions of corticomedullary endothelial cells (28). ATP depletion of cultured endothelial cells induces dephosphorylation/activation of $\mathrm{ADF} /$ cofilin, resulting in actin depolymerization and abnormal F-actin aggregate formation (29). These cellular actin changes alter the integrity of the vascular endothelium, leading to collapse of the endothelial barrier, which results in increased endothelial permeability causing increased interstitial edema, changes in vascular reactivity, increased leukocyte adherence, and compromised coagulation function $(\underline{27}, \underline{28})$.

Patients suffering from acute renal failure have increased levels of proinflammatory and antiinflammatory cytokines, and these high levels are associated with an increased mortality rate (25). Cytokine production can be stimulated by materials released as a result of tissue damage, by bacterial or viral particles, and by cytokines themselves. Particularly potent cytokine inducers include bacterial endotoxins, interleukins, interferons, tumor necrosis factors (TNF), and transforming growth factors. Proinflammatory and anti-inflammatory cytokines, in addition to soluble inhibitors of proinflammatory cytokines, make up the cytokine network. Three proinflammatory cytokines, IL-1 $\alpha$, IL-6, and TNF- $\alpha$, increase immune system activity and mediate inflammation to induce widespread changes in metabolism $(25,30)$. Cytokines can induce hemodynamic imbalance and cell/organ dysfunction in the systemic circulation. Endothelial cells play a crucial role in this process since they are among the most dynamic and biologically active components of the circulatory system and may mediate the inflammatory phenotype. TNF- $\alpha$, IL-1 $\alpha$, and IL-6, released by injured epithelial and inflammatory cells, affect the permeability of the endothelium by altering cell-cell and cell-substrate attachments. These changes are known to be mediated by actin cytoskeletal alterations, but the mechanism is unknown. Therefore, the goal of this study is to further the understanding of the mechanisms involved in cytokineinduced F-actin polymerization and reorganization in endothelial cells.

\section{MATERIALS AND METHODS}

Cell culture. Microvascular endothelial cells of murine pancreatic origin (Mile-Sven, MS1 cells, American Type Culture Collection, Manassas, VA) were grown in DMEM, pH 7.2, supplemented with 4 mM Lglutamine, $1.5 \mathrm{~g} / \mathrm{l}$ sodium bicarbonate, $4.5 \mathrm{~g} / \mathrm{l}$ glucose, $5 \% \mathrm{FBS}$, and $1 \mathrm{mg} / \mathrm{ml}$ penicillin-streptomycin (Sigma, St. Louis, MO). Cells were grown to $\sim 70 \%$ confluence before being used in experimental protocols, unless otherwise indicated.

Cellular treatment with TNF- $\alpha$, IL-1 $\alpha$, IL-6, and Y-27632. MS1 cells were exposed to increasing concentrations of IL-1 $\alpha(0.25,0.5,1.0,2.0 \mathrm{U} / \mathrm{ml}), \mathrm{IL}-6$ (5.0, 10, 20, $40 \mathrm{ng} / \mathrm{ml})$, TNF- $\alpha$ (50, 100, 200, and $400 \mathrm{U} / \mathrm{ml})$ or to a cytokine cocktail of IL-1 $\alpha(0.25 \mathrm{U} / \mathrm{ml})$, IL-6 (10 ng/ml), and TNF- $\alpha$ (400 $\mathrm{U} / \mathrm{ml}$ ) for $3 \mathrm{~h}$ [human IL-1a (catalog no. 200-01A-2UG), human TNF- $\alpha$ (catalog no. 300-01A- 
10UG), and human IL-6 (catalog no. 200-06-5UG), PeproTech, Rocky Hill, NJ]. Y-27632, a specific inhibitor of the RhoA effector kinase P160-ROCK, diluted in distilled water, was used to inhibit P160ROCK (Calbiochem) (8). MS1 cells were pretreated with inhibitory Y-27632 (10 $\mu \mathrm{M})$ for 30 min at $37^{\circ} \mathrm{C}$ in a $5 \% \mathrm{CO}_{2}$ incubator. In addition, $\mathrm{MS} 1$ cells were pretreated with $\mathrm{Y}-27632(10$ or $20 \mu \mathrm{M})$ for $30 \mathrm{~min}$ and then incubated for $3 \mathrm{~h}$ in the cytokine cocktail at $37^{\circ} \mathrm{C}$ in the $5 \% \mathrm{CO}_{2}$ incubator. Values were analyzed using Student's $t$-test and ANOVA, with statistical significance achieved at $P \leq 0.05$.

Small interfering RNA RhoA knockdown. MS1 cells were grown to 100\% confluence in a T-75 flask. Cells were trypsinized, resuspended in growth medium with FBS (0.5\%), and cell suspensions were plated on sterile glass coverslips in 12-well plates at 20\% confluence. Effectene (Qiagen, Germantown, MD) transfection reagents and small interfering (si)RNA [0.5 $\mu \mathrm{g}$ (40 pmol/transfection)], RhoA (catalog no. sc-29471), and control scrambled siRNA (catalog no. sc-37007, Santa Cruz Biotechnology, Santa Cruz, CA) were mixed according to the manufacturer's protocol. The transfection mixture was added to cell suspensions immediately before plating. The transfection medium was removed after 6-h exposure and replaced with growth medium plus 0.5\% FBS. Cells were adherent at this time. After $48 \mathrm{~h}, 400 \mathrm{U} / \mathrm{ml}$ TNF- $\alpha$ (PeproTech) was added to the appropriate wells and incubated an additional $4 \mathrm{~h}$. Cells were then fixed as below for immunofluorescence (4\% paraformaldehyde/PBS) or lysed with $200 \mu \mathrm{l}$ of $25 \mathrm{mM}$ Tris, pH 7.5, $150 \mathrm{mM}$ K acetate, $5 \mathrm{mM}$ EDTA, $5 \mathrm{mM}$ EGTA, $10 \mathrm{mM}$ DTT, $50 \mu \mathrm{M}$ butylated hydroxytoluene, $10 \%$ glycerol, $1 \%$ Triton X-100/60 mM octyl- $\beta$-D-glucopyranoside, and protease inhibitors ( $1 \mathrm{mM}$ PMSF, $1 \mathrm{mM}$ benzamidine, $1 \mu \mathrm{g} / \mathrm{ml}$ pepstatin A, $40 \mu \mathrm{g} / \mathrm{ml}$ bestatin, $50 \mu \mathrm{g} / \mathrm{ml}$ leupeptin, $2 \mu \mathrm{g} / \mathrm{ml}$ aprotinin). Fixed cells were rinsed with PBS and labeled with rhodamine-phalloidin (Invitrogen). Slides were viewed and photographed using a Zeiss LSM-510 confocal microscope and a $\times 631.2$ numerical aperture (NA) water-immersion objective lens. Cell lysates were prepared for SDSPAGE, and Western blots were probed with anti-RhoA (Santa Cruz Biotechnology) to determine the extent of RhoA knockdown.

SDS-PAGE and Western analysis. MS1 cellular proteins were extracted in a $2 \%$ SDS buffer (2\% SDS, 10 $\mathrm{mM}$ Tris, $\mathrm{pH}$ 7.6, $10 \mathrm{mM} \mathrm{NaF}, 5 \mathrm{mM}$ DTT, and $2 \mathrm{mM}$ EGTA) and boiled for $3-5 \mathrm{~min}$. Protein concentration was determined by the filter dye-binding assay (17). Equal protein concentrations (10 $\mu \mathrm{g}$ total extracted protein) were loaded in each lane, and the separated proteins were transferred to a polyvinylidene fluoride (PVDF) membrane, blocked with $5 \%$ nonfat dry milk or $10 \%$ newborn calf serum in Tris-buffered saline with Tween. For immunodetection, the PVDF membrane was probed with the rabbit primary antibody to the phosphopeptide of pADF/pcofilin (1:1,0oo; a generous gift of Dr. James Bamburg, Colorado State University, Fort Collins, CO) followed by horseradish peroxidaseconjugated goat anti-rabbit secondary antibodies (1:30,000; Southern Biotechnology, Birmingham, AL). Protein bands were detected by enhanced chemiluminescence (Pierce, Rockford, IL) on Biomax film (Kodak, Rochester, NY).

Immunofluorescence. MS1 cells were fixed in 4\% paraformaldehyde, $\mathrm{pH} 7.4$, for $30 \mathrm{~min}$, washed in PBS, and permeabilized in PBS containing 0.05\% Triton X-100 (Sigma) for $10 \mathrm{~min}$ at room temperature. The cells were then blocked with PBS containing $2 \%$ defatted BSA (Sigma) for $30 \mathrm{~min}$. At room temperature, F-actin was localized using Texas red-phalloidin (Molecular Probes, Eugene, OR) and DAPI $(2 \mu \mathrm{g} / \mathrm{ml})$ or TO-PRO-3 ( $1 \mu \mathrm{M}$, Molecular Probes) was used to localize the nucleus. The specimens were washed and mounted in 50:50 glycerol-PBS with 1\% 1,4-diazabicyclo $(\underline{2}, \underline{2}, \underline{2})$ octane (Sigma) to minimize photobleaching. Images were collected with a MRC-1024 laser-scanning confocal microscope (Bio-Rad, Hercules, CA) on a Nikon Diaphot 200 inverted stand using a $\times 60$ water objective, NA 1.2, or a $\times 100$ oil-immersion objective, NA 1.4 (Nikon, Melville, NY).

Measurement of RhoA activity. Affinity isolation was carried out as described previously (12) with the modification that MS1 cells were grown in 5\% FBS/DMEM in 100-mm plates. On the day of the experiment, cells were washed with $\mathrm{HBSS}\left(37^{\circ} \mathrm{C}\right)$ and then incubated in $5 \mathrm{ml}$ of $0.5 \% \mathrm{FBS} / \mathrm{DMEM}$ with or without cytokines. After $4 \mathrm{~h}$, the cells were rinsed with $\operatorname{HBSS}\left(37^{\circ} \mathrm{C}\right)$. One milliliter of cold extraction 
buffer $A$ [25 mM Tris ( $\mathrm{pH} 7.5$ at $4^{\circ} \mathrm{C}$ ), $150 \mathrm{mM}$ potassium acetate, $5 \mathrm{mM}$ EDTA, $5 \mathrm{mM}$ EGTA, $10 \mathrm{mM}$ DTT, $1 \%$ Triton X-100, $60 \mathrm{mM} n$-octyl- $\beta$-D-glucopyranoside, $50 \mu \mathrm{M}$ butylated hydroxytoluene, $1 \mathrm{mM}$ PMSF, $1 \mathrm{mM}$ benzamidine, $2 \mu \mathrm{g} / \mathrm{ml}$ aprotinin (Roche Molecular Biochemicals, Indianapolis, IN), 1 $\mu \mathrm{g} / \mathrm{ml}$ pepstatin A (Roche Molecular Biochemicals), $50 \mu \mathrm{g} / \mathrm{ml}$ leupeptin (Peptides International, Osaka, Japan), and $40 \mu \mathrm{g} / \mathrm{ml}$ bestatin (Roche Molecular Biochemicals)] was added to the $100-\mathrm{mm}$ plate and incubated on ice for $10 \mathrm{~min}$ with periodic manual rocking to evenly distribute the extraction buffer. The detergent extract was removed and centrifuged briefly at $1,500 \mathrm{~g}$. Twenty-five microliters of the soluble extract was mixed with $35 \mu \mathrm{l}$ of the GTP-RhoA trap glutathione agarose-bound glutathione- $S$ transferase Rho-kinase binding domain (GST-ROK-BD) to assay for RhoA activity. The extract-treated beads were incubated at $4^{\circ} \mathrm{C}$ for $1 \mathrm{~h}$ on a rotator and then rinsed three times with $500 \mu \mathrm{l}$ of buffer $A$ without detergent or protease inhibitors. The depleted fraction was precipitated with $10 \%$ trichloroacetic acid, rinsed with 70\% ethanol-acetone, dried, and dissolved in SDS sample buffer [50 mM Tris 7.5, 2\% SDS, $5 \% \beta$-mercaptoethanol, $6 \mathrm{M}$ urea, bromophenol blue]. The bound fraction was dried in a vacuum and solubilized in SDS sample buffer. Bound and unbound fractions for each time point were run on a 15\% SDS-PAGE polyacrylamide gel (BioWhittaker Molecular Applications, Rockland, ME). This was followed by Western blotting and immunostaining with $1 \mu \mathrm{g} / \mathrm{ml}$ anti-RhoA antibody (26C4, Santa Cruz Biotechnology) followed by horseradish peroxidase-conjugated goat anti-mouse secondary antibody (Jackson ImmunoResearch, West Grove, PA). Blots were visualized with enhanced chemiluminescence (ECL; Amersham Pharmacia Biotech, Piscataway, NJ) and Biomax ML film (Kodak). To determine the ratio of bound to unbound GTP-RhoA, film images were digitized and the optical density of each band was quantified with a Fluor-S MultiImager with Quantity One 4.1 software (Bio-Rad Laboratories).

Nucleotide determinations. Nucleotide determinations were performed on a HPLC system equipped with a 4- $\mu$ m Nova-Pak $\mathrm{C}_{18}$ cartridge $(100 \times 8-\mathrm{mm}$ internal diameter) and a radial compression chamber (Waters, Milford, MA). The buffer consisted of $20 \%$ acetonitrile, $10 \mathrm{mM}$ ammonium phosphate, and 2 $\mathrm{mM}$ PIC Reagent A ion-pairing reagent (Waters) and was run isocratically at $2 \mathrm{ml} / \mathrm{min}$ (12). Samples were diluted in half with $\mathrm{ddH}_{2} \mathrm{O}$, and the injection volume was $100 \mu \mathrm{l}$. A Hewlett-Packard Chemstation model 1100 was used (Hewlett-Packard, Wilmington, DE), and the UV detector was set at $254 \mathrm{~nm}$. HPLC-grade nucleotide standards were use to calibrate the signals. They were run daily because the retention of the column varied with time. To test recovery, internal standards were added to the samples and recovery exceeded $90 \%$ for all nucleotides.

Fluorescence intensity measurements/statistical analysis. Average intensity measurements were obtained using Metamorph software version 4.0 (Universal Imaging, West Chester, PA) by thresholding the Texas red-phalloidin-stained cells. Intensity values were expressed as the percentage of control values. The average background values were subtracted from the average intensity. Data were analyzed using Student's $t$-test. Statistical significance was attained with $P$ values $\leq 0.05$.

\section{RESULTS}

Cytokines induce F-actin polymerization. Initial studies were undertaken to determine the effect of cytokines on F-actin polymerization in MS1 cells. This cell line, derived from murine pancreatic microvascular endothelium, which retains many properties of the microvascular endothelium (14), was used, as we considered it to be the best immortalized cell line available in the absence of a renal microvascular cell line. Cells supplemented with a cytokine cocktail ( $0.25 \mathrm{U} / \mathrm{ml}$ of IL-1a, $10 \mathrm{ng} / \mathrm{ml}$ of IL-6, and $400 \mathrm{U} / \mathrm{ml}$ of TNF- $\alpha$ ) had increased basal F-actin stress fibers both in number and density ( $\underline{\text { Fig. } 1 B}$ ) compared with cells grown in normal media supplemented with $0.5 \%$ FBS (Fig. $1 A)$. This same effect was previously observed in bovine pulmonary artery endothelial cells (21). In addition, the cytokine cocktail induced F-actin polymerization in a time-dependent manner. With continued cytokine exposure, maximum F-actin polymerization was observed at $4 \mathrm{~h}$ and remained stable for $24 \mathrm{~h}$ (data not shown). 
To confirm the data presented in Fig. 1, we imaged the Texas red-phalloidin-stained F-actin in the presence of increasing concentrations of each cytokine and the cytokine cocktail and measured the fluorescent intensity of F-actin with Metamorph software (Fig. 2). Addition of $0.25 \mathrm{U} / \mathrm{ml}$ of IL-1 $\alpha$ increased F-actin fluorescence $61 \%$, while higher IL-1 $\alpha$ concentrations resulted in F-actin fluorescence of $<0.5 \%$ FBS control. All concentrations tested for IL-6 increased F-actin fluorescence 22-35\% over control $0.5 \%$ FBS levels. In the presence of TNF- $\alpha$, F-actin fluorescence increased in a concentrationdependent manner, with $400 \mathrm{U} / \mathrm{ml} \mathrm{TNF-} \alpha$ increasing fluorescence $60 \%$ over control $0.5 \% \mathrm{FBS}$ levels. The cytokine cocktail resulted in a $20 \%$ increase in F-actin fluorescence over control $0.5 \%$ FBS levels.

Cytokines induce phosphorylation/inactivation of cofilin. Phosphorylation of the $\mathrm{NH}_{2}$-terminal serine of cofilin inactivates its actin binding activity. Inactivated cofilin can no longer sever or depolymerize Factin. To determine the effect of cytokines on the activity of cofilin, MS1 cells supplemented with 5, 0.5, and $0.5 \%$ FBS plus the cytokine cocktail were homogenized and analyzed by Western blotting using an antibody specific for the phosphorylated epitope of cofilin (Fig. 3). Compared with the pcofilin concentration of MS1 cells supplemented with 5\% FBS, a 30\% increase in pcofilin was noted in MS1 cells supplemented with $0.5 \%$ FBS, and a $62 \%$ increase in pcofilin was observed in MS1 cells supplemented with $0.5 \%$ FBS and the cytokine cocktail.

Effect of cytokine combination (IL-1 $\alpha$, IL-6, and TNF- $\alpha$ ) on RhoA activity. Since RhoA is known to regulate stress fiber formation, we next determined the effect of the cytokine cocktail on RhoA activity. A detergent cell extract of the MS1 cells was incubated with a GST-ROCK-BD-RhoA trap, and the bound RhoA was separated from the unbound GDP-RhoA (르). Densitometry of chemiluminescence films demonstrated RhoA activity increased up to $227 \pm 26 \%$ in MS1 cells after incubation with the cytokine combination $(P<0.05)$ ( Fig. 4). In all studies, a marked increase over baseline levels was observed, although the baseline varied between studies.

RhoA knockdown and the P160-ROCK inhibitor Y-27632 block cytokine-induced actin redistribution in MS1 cells.

To directly test the importance of RhoA activation in stimulating downstream signaling pathways leading to stress fiber assembly in MS1 cells, we used pooled siRNAs targeting the mouse RhoA sequence. Scrambled siRNA with no predicted target in the mouse genome was used as a control. Transfection with RhoA siRNA resulted in decreased levels of RhoA protein detected by immunoblotting at $48 \mathrm{~h}$ following transfection (Fig. $5 \mathrm{~A}$ ). RhoA levels in RhoA siRNA-transfected cells were $\sim 10 \%$ of the levels in control siRNA-transfected cells or untransfected MS1 cells (data not shown). Cells transfected with RhoA siRNA showed decreased abundance of stress fiber bundles on their basal surfaces compared with cells treated with control siRNA (Fig. 5, B1 and B2), or mock transfected cells (data not shown). We then tested whether cells depleted of RhoA still showed increased stress fiber formation in response to cytokine stimulation. We used TNF- $\alpha$ as a stimulus, since it produced the largest effect on stress fiber organization in our initial experiments (see Fig. 2). Transfection with RhoA siRNA, but not control siRNA, completely blocked the increase in stress fiber formation induced by TNF- $\alpha$ stimulation ( Fig. 5B4).

To confirm this result and identify downstream effectors of RhoA that could mediate the cytokine response, we used Y-27632, a specific inhibitor of the RhoA effector kinase P160-ROCK. Utilizing quantitative confocal microscopy to measure F-actin stress fibers, we confirmed that F-actin stress fiber formation significantly increased $34 \%$ over control levels in cells treated with the cytokine cocktail for 3 h ( Fig. 6). In cells treated with Y-27632, a significant reduction in F-actin fluorescence intensity to $78 \%$ of control levels occurred. Pretreatment of cells with the P160-ROCK inhibitor Y-27632 for 30 min followed by cytokine cocktail exposure for $3 \mathrm{~h}$ yielded fluorescence intensities similar to baseline levels (2\% increase over control levels) (Fig. 6). Western blot analysis of MS1 cellular extracts demonstrated a $73 \%$ increase in pcofilin in the presence of the cytokine cocktail over control cells, no detectable pcofilin in the presence of the Y-27632 inhibitor alone, but an increase in pcofilin to $55 \%$ of control levels when 
exposed to Y-27632 for 30 min followed by incubation with the cytokine cocktail for $3 \mathrm{~h}$ (Fig. 6 F ).

Effect of cytokines on free nucleotides in MS1 cells. Analysis of the nucleotide profile of MS1 cells grown

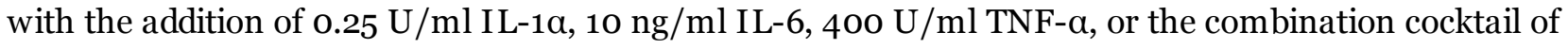
cytokines demonstrated there were no significant alterations in the nucleotide pool (Table 1). Nucleotide levels decreased for all conditions, but not to $25 \%$ of control values, which occurs with antimycin A treatment and is required for polymerization of ADP-actin (3).

\section{DISCUSSION}

Cellular stress induces dramatic changes in actin cytoskeleton dynamics and cellular organization, but the underlying causal mechanisms are still not well understood $(5, \underline{18})$. In response to an ischemic insult to the kidney, many factors are released, including cytokines. Cytokines, particularly IL-1 $\alpha$, IL-6, and TNF- $\alpha$, are known to orchestrate various inflammatory reactions influencing endothelial cell permeability by altering cell-cell and cell-extracellular matrix attachments $(\underline{20}, \underline{23}, \underline{25})$. It is not known whether these cytokines play a role in the signaling pathways leading to actin filament severing, depolymerization, and abnormal actin aggregate formation that are observed in response to ischemiainduced acute kidney injury. In this study, utilizing a murine pancreatic microvascular cell line, we questioned whether these particular cytokines, independently or in combination, contributed to the dramatic actin cytoskeleton rearrangement observed in response to renal ischemia in endothelial cells. Although it would have been preferable to use renal microvascular cells in this study, immortalized cell lines derived from the renal microvasculature are not currently available, and it is impractical to isolate a sufficient quantity of cells in primary culture for the studies described here. Microvascular endothelial cells from different organs are more similar to one another in their gene expression profile than they are to endothelial cells from large vessels ( $\mathrm{Z}$ ), so the choice of a microvascular cell line, albeit from the pancreas instead of the kidney, provides a reasonable model for injury to the renal microvasculature.

Previous studies have demonstrated that the actin-depolymerizing and -severing proteins ADF and cofilin are dephosphorylated and activated during renal ischemia, suggesting that these proteins are positioned to play a significant role in the observed ischemia-induced actin reorganization $(\underline{2}, \underline{24}, \underline{29})$. However, exactly what extracellular factors are involved in their activation has not been determined.

Studies of the RhoA signaling cascade, a potential upstream regulator of ADF/cofilin, demonstrated that ischemia or ATP depletion reduced RhoA and ROCK p16o activity (12). Decreased activity of ROCK p160 would be expected to lead to decreased activity of the serine/threonine kinases LIMK1 and LIMK2 and consequently an increase in dephosphorylated (active) $\mathrm{ADF} /$ cofilin. The resulting higher levels of activated $\mathrm{ADF} /$ cofilin proteins would cause more depolymerization and severing of actin filaments during renal ischemia. In this study, we demonstrate that when cytokines are present, as they are in vivo, the situation is more complicated, presenting evidence that the proinflammatory cytokines used here could antagonize the effect of ischemia on RhoA signaling. Cytokines increased RhoA activity over baseline, and the abundance and thickness of endothelial cell basal stress fibers were increased in the presence of the individual cytokines and the cytokine cocktail. It is noteworthy that the combination of cytokines was less effective in inducing stress fiber formation than the optimal dose of each of the individual cytokines used alone, indicating some interference between the signaling pathways downstream of their respective receptors. Using siRNA to knock down levels of RhoA to $\sim 10 \%$ of control levels completely blocked any effect of cytokines on stress fiber organization, in agreement with a key role for RhoA signaling in mediating the cytokine effect on cytoskeletal organization. Importantly, other than the changes in organization to the basal cytoskeleton, there were no gross morphological changes in cell morphology or any other indications that RhoA knockdown to these levels caused significant loss of cell viability.

For TNF- $\alpha$, and possibly other cytokines, recent work suggests possible signaling mechanisms that could contribute to the RhoA activation observed here. TNF- $\alpha$ activates IKк $\beta$, which phosphorylates the 
tuberous sclerosis complex TSC1 subunit on serine 511, leading to dissociation of the complex and destabilization of TSC2 (모). TSC2 has been shown to act to downregulate the level of RhoA activity (10), and so the predicted effect of TNF- $\alpha$ treatment would be exactly the increased RhoA activity that we observed in this study.

In addition to the enhanced activity of RhoA, we showed that inhibition of the RhoA effector ROCK p160 with the specific inhibitor Y-2763 significantly reduced actin stress fibers in endothelial cells, consistent with decreased ROCK activity leading to decreased LIM1/2 activity and accumulation of active ADF/cofilin. Interestingly, when the cells were first incubated with the Y-27632 inhibitor and then incubated with the inhibitor and the cytokine cocktail, the actin stress fiber density returned to approximately the same fluorescence levels observed under control physiological conditions. Also, under these same conditions, the level of phosphorylated/inactive cofilin increased to $55 \%$ of baseline conditions. These results suggest cytokines can partially override the effects of the Y-27632 inhibitor, but not completely, as the level of actin stress fiber fluorescence did not rise to the levels of incubation with cytokines alone. This is in contrast to the effect of RhoA knockdown, which completely ablated any cytokine effect on stress fibers, showing that ROCK-independent signaling mechanisms activated by cytokines probably operate downstream of RhoA.

In the presence of the cytokine cocktail, phosphorylation/inactivation of cofilin also increased. These results also demonstrate cytokines signal through the RhoA-ROCKp16o pathway to inactivate $\mathrm{ADF} /$ cofilin to promote actin polymerization. Finally, since Y-27632, unlike RhoA siRNA, did not completely block the cytokine effect, they suggest cytokines must also utilize another signaling cascade downstream of RhoA to promote stress fiber formation. Studies have demonstrated that a balance between kinase and phosphatase pathways determines the level of $\mathrm{ADF} /$ cofilin phosphorylation (4, $\underline{16}$, 26). Therefore, it is possible the $\mathrm{ADF} /$ cofilin-specific phosphatase slingshot may be regulated by cytokines, decreasing dephosphorylation of $\mathrm{ADF} /$ cofilin proteins. Alternatively, cytokines, through activation of RhoA, probably activate other signaling cascades through alternative RhoA effectors, such as the formin mDia. Activated mDia partners with the actin binding protein profilin to increase actin polymerization (31).

In summary, our studies suggest that release of cytokines, in response to renal ischemia, did not contribute to the observed breakdown and reorganization of the actin cytoskeleton that we previously observed with renal ischemia (Table 2). In fact, actin stress fibers were increased, not decreased and abnormal aggregates were rarely seen, while many are observed with ATP depletion. The RhoA signaling cascade was activated by the cytokines, inducing phosphorylation/inactivation of ADF/cofilin, which resulted in actin filament stabilization, while renal ischemia downregulates the RhoA signaling cascade, resulting in dephosphorylation/activation of $\mathrm{ADF} /$ cofilin and increased severing and depolymerization of actin filaments. In addition, cytokines did not affect the nucleotide levels, in contrast to the reduced nucleotide levels observed with renal ischemia. These studies suggest that, while cytokines are released during renal ischemia independently, they did not play a role in the F-actin breakdown we observed with cellular ATP depletion. The net effect of ischemic injury on the cytoskeleton in vivo, then, is a composite of the direct effects of ischemia on cytoskeletal organization, overlaid with competing effects of cytokine signaling. Cytokines may possibly act as stabilizing agents to prevent complete ischemia-induced actin cytoskeleton destruction and may work in concert with other factors to provide a means for actin cytoskeleton and cellular recovery. The degree to which the normal cytokine signaling mechanisms that utilize kinases and phosphatases can operate under the low-ATP conditions during the actual ischemic period is a question that requires further investigation. Once ATP levels recover during reperfusion, however, cytokine signaling is likely to predominate. Further work is required to determine how these competing mechanisms operate in vivo and to understand the additional complexities introduced by other factors such as hypoxia and the presence of other immune modulators including anti-inflammatory factors that are also characteristics of the ischemic milieu. 
This work was supported by National Institutes of Health Grants Ro1-DK-069408 (B. A. Molitoris) and Ro1-DK-053194 (S. J. Atkinson) and the Department of Veterans Affairs (B. A. Molitoris). S. L. Ashworth acknowledges support from the Vice-President for Research, University of Maine.

\section{Acknowledgments}

We thank Dr. James Bamburg (Colorado State University) for anti-phospho-cofilin antisera.

\section{Notes}

The costs of publication of this article were defrayed in part by the payment of page charges. The article must therefore be hereby marked "advertisement" in accordance with 18 U.S.C. Section 1734 solely to indicate this fact.

\section{REFERENCES}

1. Arber S, Barbayannis FA, Hanser H, Schneider C, Stanyon CA, Bernard O, Caroni P. Regulation of actin dynamics through phosphorylation of cofilin by LIM-kinase. Nature 393: 805-809, 1998.

[PubMed: 9655397]

2. Ashworth SL, Sandoval RM, Hosford M, Bamburg JR, Molitoris BA. Ischemic injury induces ADF relocalization to the apical domain of rat proximal tubule cells. Am J Physiol Renal Physiol 280: F886F894, 2001. [PubMed: 11292632]

3. Atkinson SJ, Hosford MA, Molitoris BA. Mechanism of actin polymerization in cellular ATP depletion. J Biol Chem 279: 5194-5199, 2004. [PubMed: 14623892]

4. Bamburg JR Proteins of the ADF/cofilin family: essential regulators of actin dynamics. Annu Rev Cell Dev Biol 15: 185-230, 1999. [PubMed: 10611961]

5. Bonventre JV, Weinberg JM. Recent advances in the pathophysiology of ischemic acute renal failure. J Am Soc Nephrol 14: 2199-2210, 2003. [PubMed: 12874476]

6. Brodsky SV, Yamamoto T, Tada T, Kim B, Chen J, Kajiya F, Goligorsky MS. Endothelial dysfunction in ischemic acute renal failure: rescue by transplanted endothelial cells. Am J Physiol Renal Physiol 282: F1140-F1149, 2002. [PubMed: 11997331]

7. Chi JT, Chang HY, Haraldsen G, Jahnsen FL, Troyanskaya OG, Chang DS, Wang Z, Rockson SG, van de Rijn M, Botstein D, Brown PO. Endothelial cell diversity revealed by global expression profiling. Proc Natl Acad Sci USA 100: 10623-10628, 2003. [PMCID: PMC196854] [PubMed: 12963823]

8. Chitaley K, Wingard CJ, Clinton Webb R, Branam H, Stopper VS, Lewis RW, Mills TM. Antagonism of Rho-kinase stimulates rat penile erection via a nitric oxide-independent pathway. Nat Med 7: 119122, 2001. [PubMed: 11135626]

9. Edwards DC, Gill GN. Structural features of LIM kinase that control effects on the actin cytoskeleton. J Biol Chem 274: 11352-11361, 1999. [PubMed: 10196227]

10. Goncharova E, Goncharov D, Noonan D, Krymskaya VP. TSC2 modulates actin cytoskeleton and focal adhesion through TSC1-binding domain and the Rac1 GTPase. J Cell Biol 167: 1171-1182, 2004. [PMCID: PMC2172598] [PubMed: 15611338]

11. Hall A Rho GTPases and the actin cytoskeleton. Science 279: 509-514, 1998. [PubMed: 9438836] 12. Hallett MA, Dagher PC, Atkinson SJ. Rho GTPases show differential sensitivity to nucleotide triphosphate depletion in a model of ischemic cell injury. Am J Physiol Cell Physiol 285: C129-C138, 
2003. [PubMed: 12620811]

13. Lee DF, Kuo HP, Chen CT, Hsu JM, Chou CK, Wei Y, Sun HL, Li LY, Ping B, Huang WC, He X, Hung JY, Lai CC, Ding Q, Su JL, Yang JY, Sahin AA, Hortobagyi GN, Tsai FJ, Tsai CH, Hung MC. IKK beta suppression of TSC1 links inflammation and tumor angiogenesis via the mTOR pathway. Cell 130: 440-455, 2007. [PubMed: 17693255]

14. Lu LH, Oh DJ, Dursun B, He Z, Hoke TS, Faubel S, Edelstein CL. Increased macrophage infiltration and fractalkine expression in cisplatin-induced acute renal failure in mice. J Pharmacol Exp Ther 324: 111-117, 2008. [PubMed: 17932247]

15. Maekawa M, Ishizaki T, Boku S, Watanabe N, Fujita A, Iwamatsu A, Obinata T, Ohashi K, Mizuno K, Narumiya S. Signaling from Rho to the actin cytoskeleton through protein kinases ROCK and LIMkinase. Science 285: 895-898, 1999. [PubMed: 10436159]

16. Meberg PJ, Ono S, Minamide LS, Takahashi M, Bamburg JR. Actin depolymerizing factor and cofilin phosphorylation dynamics: response to signals that regulate neurite extension. Cell Motil Cytoskeleton 39: 172-190, 1998. [PubMed: 9484959]

17. Minamide LS, Bamburg JR. A filter paper dye-binding assay for quantitative determination of protein without interference from reducing agents or detergents. Anal Biochem 190: 66-70, 1990. [PubMed: 2285147]

18. Molitoris BA Actin cytoskeleton in ischemic acute renal failure. Kidney Int 66: 871-883, 2004. [PubMed: 15253754]

19. Ohashi K, Nagata K, Maekawa M, Ishizaki T, Narumiya S, Mizuno K. Rho-associated kinase ROCK activates LIM-kinase 1 by phosphorylation at threonine 508 within the activation loop. J Biol Chem 275: 3577-3582, 2000. [PubMed: 10652353]

20. Okusa MD The inflammatory cascade in acute ischemic renal failure. Nephron 90: 133-138, 2002. [PubMed: 11818695]

21. Petrache I, Verin AD, Crow MT, Birukova A, Liu F, Garcia JG. Differential effect of MLC kinase in TNF- $\alpha$-induced endothelial cell apoptosis and barrier dysfunction. Am J Physiol Lung Cell Mol Physiol 280: L1168-L1178, 2001. [PubMed: 11350795]

22. Pollard TD, Borisy GG. Cellular motility driven by assembly and disassembly of actin filaments. Cell 112: 453-465, 2003. [PubMed: 12600310]

23. Ramesh G, Reeves WB. Inflammatory cytokines in acute renal failure. Kidney Int Suppl: S56-S61, 2004.

24. Schwartz N, Hosford M, Sandoval RM, Wagner MC, Atkinson SJ, Bamburg J, Molitoris BA. Ischemia activates actin depolymerizing factor: role in proximal tubule microvillar actin alterations. Am J Physiol Renal Physiol 276: F544-F551, 1999.

25. Simmons EM, Himmelfarb J, Sezer MT, Chertow GM, Mehta RL, Paganini EP, Soroko S, Freedman S, Becker K, Spratt D, Shyr Y, Ikizler TA. Plasma cytokine levels predict mortality in patients with acute renal failure. Kidney Int 65: 1357-1365, 2004. [PubMed: 15086475]

26. Soosairajah J, Maiti S, Wiggan O, Sarmiere P, Moussi N, Sarcevic B, Sampath R, Bamburg JR, Bernard O. Interplay between components of a novel LIM kinase-slingshot phosphatase complex regulates cofilin. EMBO J 24: 473-486, 2005. [PMCID: PMC548651] [PubMed: 15660133]

27. Stevens T, Garcia JG, Shasby DM, Bhattacharya J, Malik AB. Mechanisms regulating endothelial cell barrier function. Am J Physiol Lung Cell Mol Physiol 279: L419-L422, 2000. [PubMed: 10956614] 
28. Sutton TA, Mang HE, Campos SB, Sandoval RM, Yoder MC, Molitoris BA. Injury of the renal microvascular endothelium alters barrier function after ischemia. Am J Physiol Renal Physiol 285: F191-F198, 2003. [PubMed: 12684225]

29. Suurna MV, Ashworth SL, Hosford M, Sandoval RM, Wean SE, Shah BM, Bamburg JR, Molitoris BA. Cofilin mediates ATP depletion-induced endothelial cell actin alterations. Am J Physiol Renal Physiol 290: F1398-F1407, 2006. [PubMed: 16434575]

30. van der Poll T, van Deventer SJ. Cytokines and anticytokines in the pathogenesis of sepsis. Infect Dis Clin North Am 13: 413-426, ix, 1999. [PubMed: 10340175]

31. Vicente-Manzanares M, Rey M, Perez-Martinez M, Yanez-Mo M, Sancho D, Cabrero JR, Barreiro $\mathrm{O}$, de la Fuente H, Itoh K, Sanchez-Madrid F. The RhoA effector $\mathrm{mDia}$ is induced during $\mathrm{T}$ cell activation and regulates actin polymerization and cell migration in T lymphocytes. J Immunol 171: 1023-1034, 2003. [PubMed: 12847276]

32. Yang N, Higuchi O, Ohashi K, Nagata K, Wada A, Kangawa K, Nishida E, Mizuno K. Cofilin phosphorylation by LIM-kinase 1 and its role in Rac-mediated actin reorganization. Nature 393: 809812, 1998. [PubMed: 9655398]

\section{Figures and Tables}

Fig. 1.
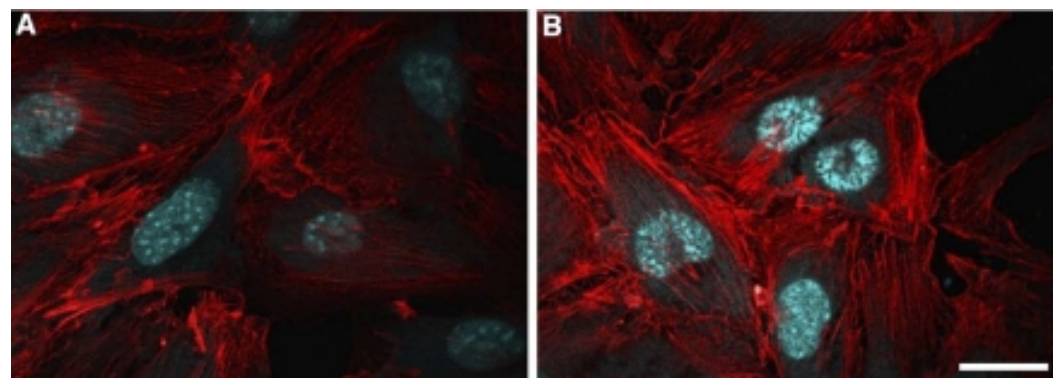

Cytokines induced accumulation of dense F-actin stress fibers in MS1 cells. Under physiological conditions $(A)$, Texas red-phalloidin stained basal F-actin stress fibers and cortical F-actin. Cells incubated under similar conditions, but supplemented for $4 \mathrm{~h}$ with a cytokine cocktail containing IL-1 $\alpha$ (o.25 U/ml), IL-6 (10 ng/ml), and TNF- $\alpha$ (40o U/ml), exhibited substantially increased Texas red-phalloidin-stained basal stress fibers, both in thickness and number $(B)$. Bar $=10 \mu \mathrm{m}$.

Fig. 2.

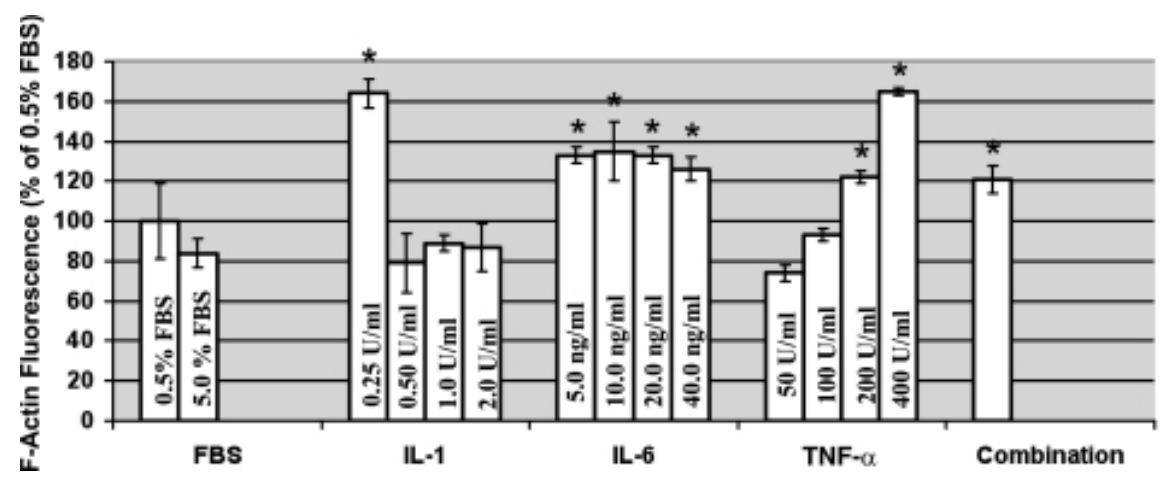

Cytokines increased cellular F-actin content in MS1 cells. Using confocal microscopy and Metamorph software, F-actin fluorescence of MS1 cells treated with cytokines IL-1 $\alpha$, IL-6, and TNF- $\alpha$ was quantified. F-actin fluorescence increased $61 \%$ in cells incubated with $0.25 \mathrm{U} / \mathrm{ml}$ of IL-1, while higher concentrations of IL-1a 
reduced F-actin fluorescence to $<0.5 \%$ FBS control levels. All IL-6 concentrations increased F-actin fluorescence $22-35 \%$. When TNF- $\alpha$ was incubated with MS1 cells, F-actin fluorescence increased in a dosedependent manner, while incubation of the cells with the cytokine cocktail $(0.25 \mathrm{U} / \mathrm{ml}$ of IL-1 $\alpha, 10 \mathrm{ng} / \mathrm{ml}$ of IL6 , and $400 \mathrm{U} / \mathrm{ml}$ of TNF- $\alpha$ ) resulted in a $20 \%$ increase in F-actin fluorescence. All values are expressed as the percentage of $0.5 \% \mathrm{FBS}$ control $\left({ }^{*} P \leq 0.05\right)$.

Fig. 3.

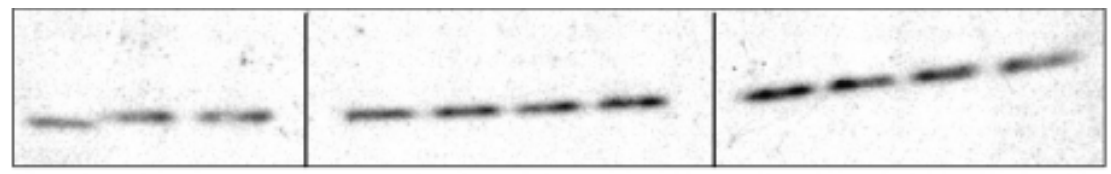
$5 \%$ FBS
$0.5 \%$ FBS 4 hr
$0.5 \%$ FBS 4 hr + Cytokines

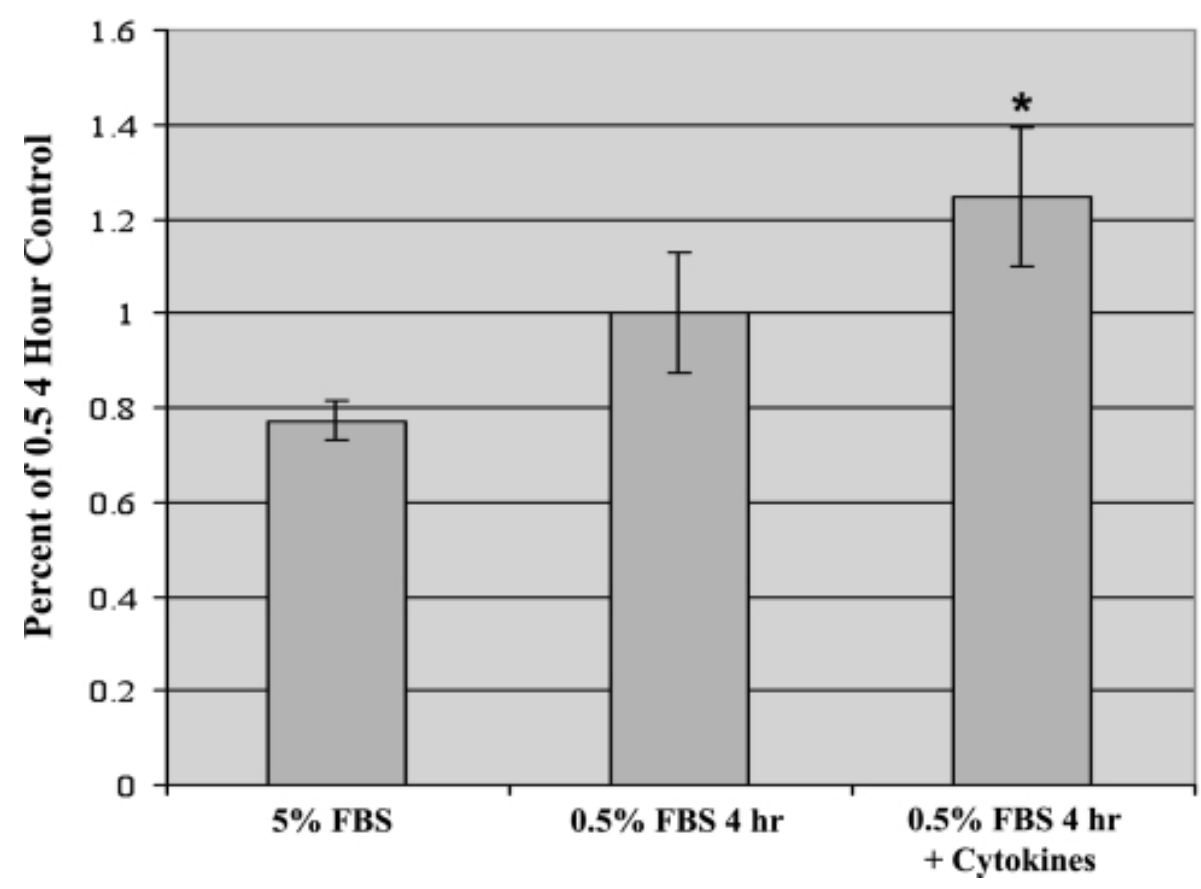

Cytokines induced phosphorylation/inactivation of cofilin in MS1 cells. To demonstrate phosphorylation of cofilin, Western blots were probed with a pADF/pcofilin-specific antibody (top). Lanes 1-3, 5\% FBS (3 replicates); lanes 4-7, 0.5\% FBS (4 replicates); lanes 8-11, 0.5\% FBS with cy tokine cocktail (see below; 4 replicates). The level of phosphorylated or inactive cofilin increased $30 \%$ in MS1 cells incubated for $4 \mathrm{~h}$ in the presence of $0.5 \%$ FBS compared with MS1 cells incubated in $5 \%$ FBS. When the cytokine cocktail combination ( $0.25 \mathrm{U} / \mathrm{ml}$ of IL- $1 \alpha, 10 \mathrm{ng} / \mathrm{ml}$ of IL-6, and $400 \mathrm{U} / \mathrm{ml}$ of TNF- $\alpha$ ) was added to MS1 cells incubated in $0.5 \% \mathrm{FBS}$, phosphorylated cofilin increased $62 \%$ over cells incubated in $5 \% \mathrm{FBS}$, and there was a $25 \%$ increase over cells incubated in $0.5 \% \mathrm{FBS}\left({ }^{*} P \leq 0.05\right)$. All lanes for the Western blots were loaded with $10 \mu \mathrm{g}$ total protein.

Fig. 4. 


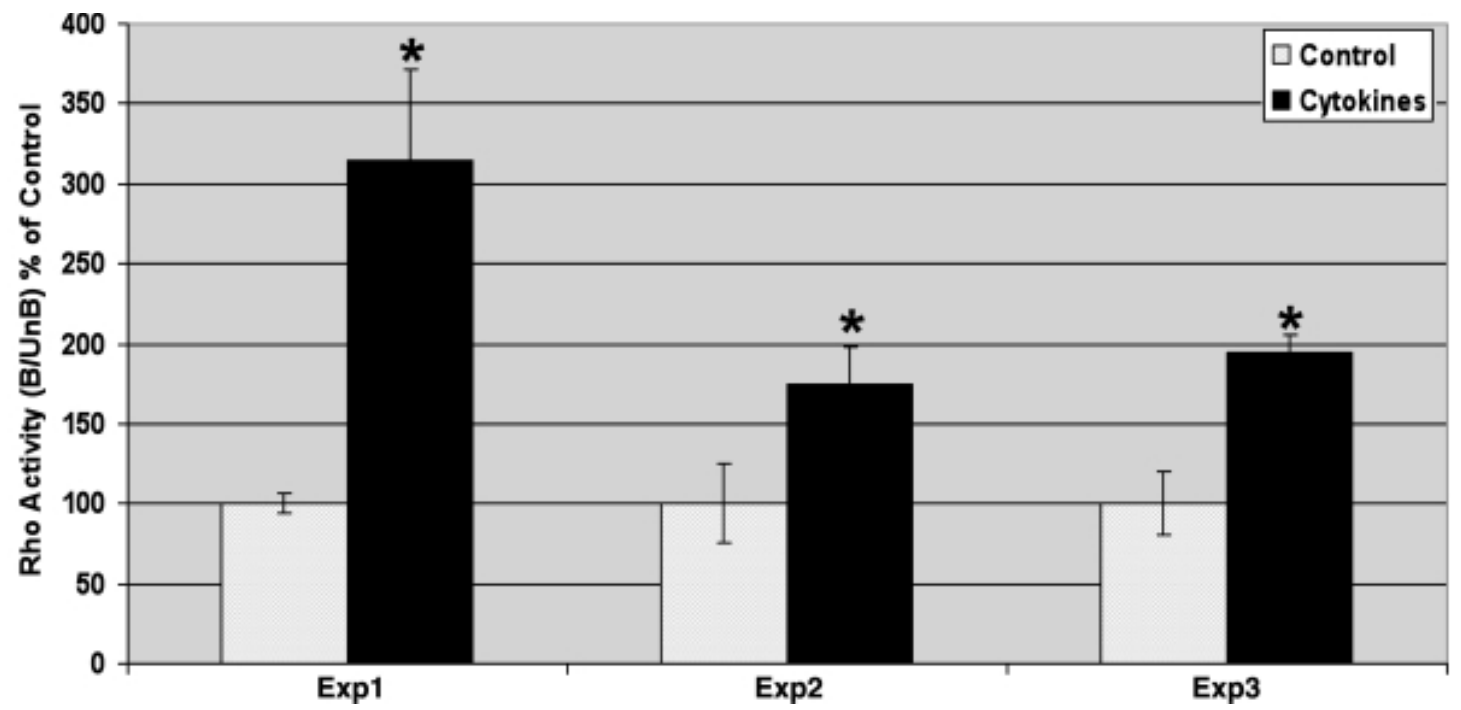

RhoA activation increased in the presence of cytokines in MS1 cells. In 3 separate experiments, RhoA activation (bound vs. unbound fraction) was significantly increased in MS1 cells incubated for $4 \mathrm{~h}$ in physiological media (containing $0.5 \%$ FBS) containing the cytokine cocktail combination ( $0.25 \mathrm{U} / \mathrm{ml}$ of IL-1 $\alpha$, $10 \mathrm{ng} / \mathrm{ml}$ of IL- 6 , and $400 \mathrm{U} / \mathrm{ml}$ of TNF- $\alpha$ ) compared with MS1 cells grown without addition of cy tokines $\left({ }^{*} P \leq\right.$ 0.05). Values, expressed as percentage of control, are means $\pm \mathrm{SD}$ of 3 replicates/experiment.

Fig. 5. 
A

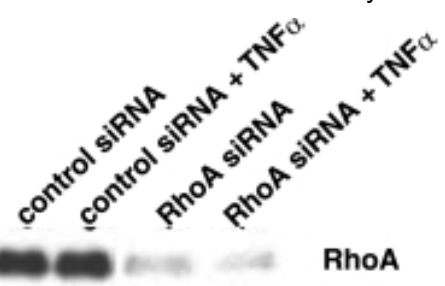

B

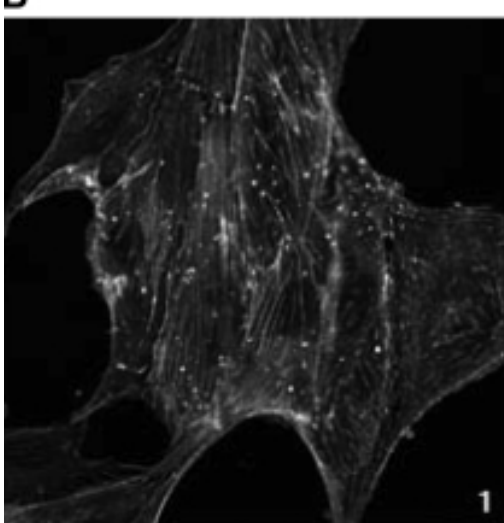

control siRNA

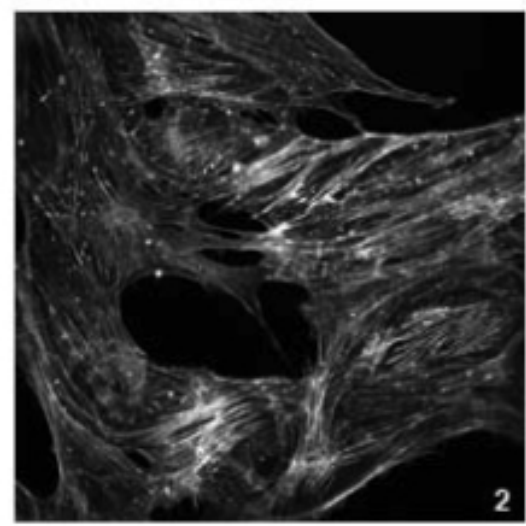

control siRNA + TNF $\alpha$

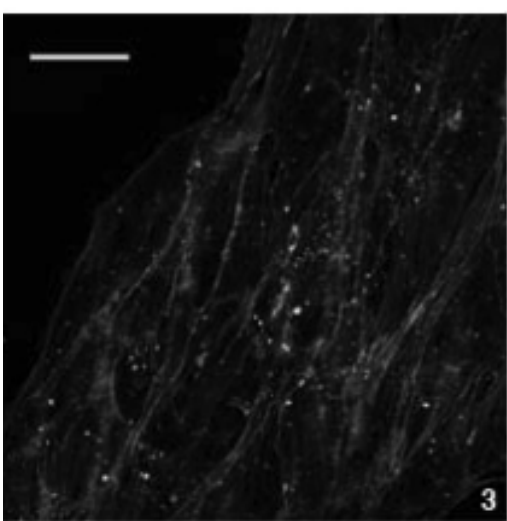

RhOA siRNA

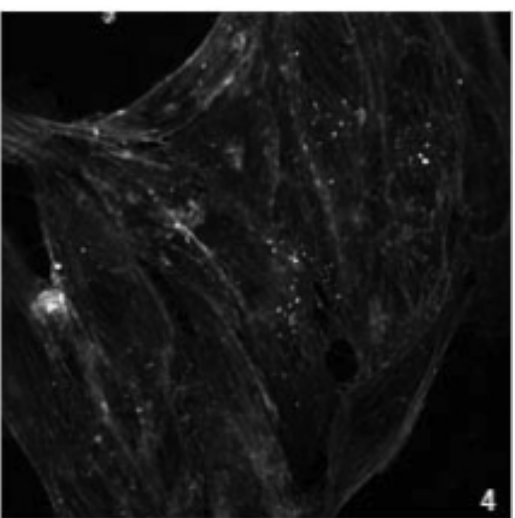

RhoA siRNA + TNF $\alpha$

Effect of RhoA knockdown on cytokine-induced stress fiber formation. A: Western blot probed with anti-RhoA of lysates from MS1 cells treated as in $B . B$ : rhodamine-phalloidin-labeled stress fibers of MS1 cells $48 \mathrm{~h}$ posttransfection with either a control siRNA (top) or small-interfering (si)RNA to RhoA (bottom). Cells were incubated with siRNA plus 4-h incubation with either 0.5 or $0.5 \%$ FBS with TNF- $\alpha$ (right). Bar $=10 \mu \mathrm{m}$.

Fig. 6. 

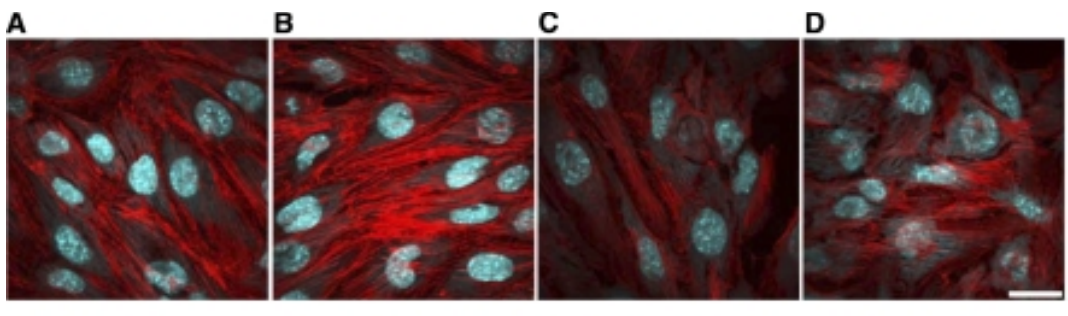

E

Cytokine Induced F-Actin Redistribution
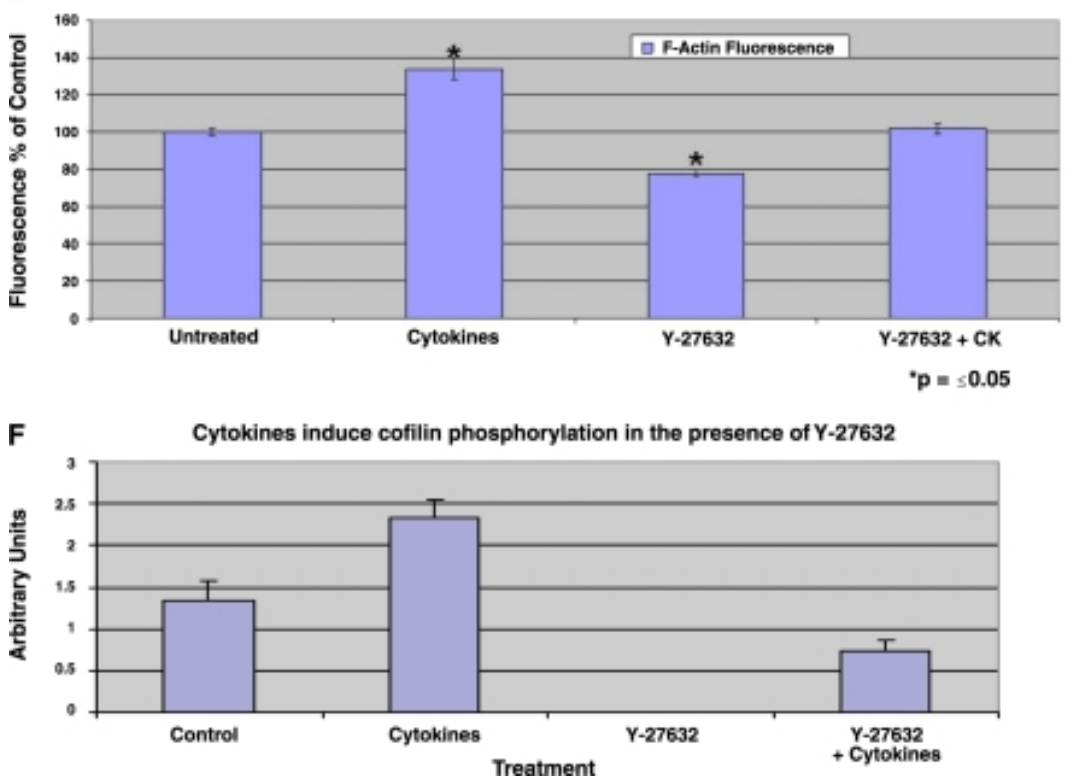

Y-27632 inhibits cy tokine-induced actin redistribution in MS1 cells. Basal F-actin stress fibers increased in MS1 cells incubated with a cy tokine cocktail combination (0.5\% FBS with $0.25 \mathrm{U} / \mathrm{ml}$ of IL-1 $\alpha, 10 \mathrm{ng} / \mathrm{ml}$ of IL-6, and $400 \mathrm{U} / \mathrm{ml}$ of TNF- $\alpha$ ) for $3 \mathrm{~h}(B)$ compared with untreated cells ( $A$; $0.5 \% \mathrm{FBS}$ alone). A decrease in basal stress fibers was observed in MS1 cells treated for 30 min with Y-27632 (10 $\mu \mathrm{M})$, a specific inhibitor of the RhoA effector kinase P16o-ROCK (C). MS1 cells exposed to Y-27 $632(10 \mu \mathrm{M})$ for 30 min before incubation with Y 27632 and the cytokine cocktail for $3 \mathrm{~h}(D)$ exhibited more basal stress fibers than Y-27632-treated cells $(C)$, significantly fewer stress fibers than cytokine-treated cells $(B)$, and approximately the same amount of stress fibers as observed in the untreated sample $(A) . D$ : F-actin is observed not only in stress fibers but also in ruffled cell edges. $E$ : F-actin content was quantitated by measuring the F-actin fluorescence with each treatment and expressed as a percentage of the untreated sample. There was a significant increase in F-actin fluorescence with treatment with cy tokines ( $34 \%$ over control levels), a significant decrease with Y-27 632 treatment ( $78 \%$ of control levels), and a return to untreated values in cells pretreated with Y-27632 and then exposed to Y-27 632 and the cytokine cocktail $(P \leq 0.05)$. $F$ : the level of phosphorylated/inactive cofilin increased almost 2 -fold in the presence of the cy tokine cocktail, decreased to nondetectable levels in the presence of the Y-27632 inhibitor and, in the presence of the inhibitor for 30 min followed by the inhibitor and cytokine cocktail for $3 \mathrm{~h}$, pcofilin levels increased to $55 \%$ of control levels. Bar $=10 \mu \mathrm{m}$.

Table 1.

Nucleotide profile of MS1 cells under physiological conditions and with cytokine treatment

\begin{tabular}{lcccc}
\hline & ATP & ADP & GTP & GDP \\
\hline $5 \% \mathrm{FBS}$ & $100 \pm 1.2$ & $100 \pm 7.2$ & $100 \pm 2.9$ & $100 \pm 9.1$ \\
& & & & \\
$0.5 \% \mathrm{FBS}$ & $79.5 \pm 2.7$ & $93.3 \pm 18.8$ & $86.6 \pm 3.5$ & $110 \pm 25.4$ \\
$0.25 \mu \mathrm{l} / \mathrm{ml} \mathrm{IL}-1 \alpha$ & $87.6 \pm 2.1$ & $104.9 \pm 5.8$ & $95.3 \pm 1.8$ & $123.8 \pm 8.2$ \\
$10 \mathrm{ng} / \mathrm{ml} \mathrm{IL-6}$ & $83.0 \pm 0.9$ & $74.0 \pm 3.0$ & $90.3 \pm 0.4$ & $90.2 \pm 7.7$ \\
$400 \mathrm{U} / \mathrm{ml} \mathrm{TNF}-\alpha$ & $78.1 \pm 1.3$ & $75.4 \pm 8.2$ & $83.4 \pm 1.8$ & $87.5 \pm 11.6$
\end{tabular}


Values are means \pm SD expressed as percentage of control (5\% FBS group) and are corrected for protein concentration. The nucleotide levels of ATP, ADP, GTP, and GDP determined by HPLC are listed for MS1 cells grown in 5\% FBS, 0.5\% FBS, and 0.5\% FBS in the presence of cytokines IL1- $\alpha$, IL-6, or TNF- $\alpha$ or a combination cocktail of all 3 cytokines.

Table 2.

Comparison of cytoskeletal alterations induced by cytokines versus ischemia/ATP depletion

\begin{tabular}{lll}
\hline & \multicolumn{2}{c}{ Cytokine Stimulation } \\
\hline Actin stress fibers & Increase & Breakdown \\
Actin aggregates & Rare & Many (large and small) \\
ATP/GTP levels & Remain stable & Decrease \\
Rho activation & Increases & Decreases \\
Pcofilin levels & Increase & Decrease \\
\hline
\end{tabular}

Endothelial cells stimulated with the cytokine cocktail demonstrated increases in actin stress fibers, Rho activation, and pcofilin levels. Actin aggregates were rarely noted, and ATP/GTP levels remained stable with incubation with cytokines. In contrast, ischemia or ATP depletion resulted in breakdown of actin stress fibers with formation of many small and large aggregates, besides decreased Rho activation and decreased pcofilin and ATP/GTP levels.

Articles from American Journal of Physiology - Renal Physiology are provided here courtesy of American Physiological Society 